\title{
Desenvolvimento de Uma Escala de Bem-Estar Subjetivo ${ }^{1}$
}

\author{
Anelise Salazar Albuquerque ${ }^{2}$ \\ Bartholomeu Tôrres Tróccoli \\ Universidade de Brasília
}

\begin{abstract}
RESUMO - Há poucas medidas válidas de bem-estar subjetivo adaptadas à população brasileira. Nesse estudo, diversos itens foram elaborados para o desenvolvimento de um instrumento para mensurar os três maiores componentes do bem-estar subjetivo: satisfação com a vida, afeto positivo e afeto negativo. A Escala de Bem-Estar Subjetivo (EBES) foi respondida por 795 pessoas (idade média = 35,6 anos; desvio-padrão =4,83). A análise dos componentes principais e a análise fatorial (extração dos eixos principais - PAF e rotação oblimin) revelaram os três fatores esperados: afeto positivo (21 itens, explicando $24,3 \%$ da variância, alfa = 0,95); afeto negativo (26 itens, $24,9 \%$ da variância, alfa =0,95) e satisfação-insatisfação com a vida $(15$ itens, $21,9 \%$ da variância, alfa $=0,90)$. Juntos, os três fatores explicaram 44,1 \% da variância total do construto. Os 69 itens da EBES foram analisados pela Teoria de Resposta ao Item (TRI). Os resultados demonstraram validade de construto da EBES.
\end{abstract}

Palavras-chave: bem-estar subjetivo; validação; escala.

\section{Development of a Subjective Well-Being Scale}

\begin{abstract}
There are few valid measures of subjective well-being adapted to the Brazilian population. In this study, several items were elaborated for the development of an instrument to measure the three major components of subjective well-being: satisfaction with life, positive affect and negative affect. The Subjective Well-Being Scale (EBES) was answered by 795 participants (mean age $=35.6$ years old; standard deviation $=4.83$ ). Principal components and factor analysis of their answers (extratcion of principal components - $P A F$ and direct oblimin rotation) revealed the expected three factors: positive affect (21 items, explaining $24.3 \%$ of the variance, alpha $=0.95)$; negative affect $(26$ items, $24.9 \%$ of the variance, alpha $=0.95)$ and satisfaction-dissatisfaction with life (15 items, $21.9 \%$ of the variance, alpha $=0.90$ ). Together, these three factors explained $44.16 \%$ of the total variance of the construct. The 69 items of the EBES were further analyzed using Item Response Theory (IRT). All the results supported the construct validity of the Subjective Well-Being Scale.
\end{abstract}

Key words: subjective well-being; validation; scale.

O estudo do Bem-Estar Subjetivo (BES) busca compreender a avaliação que as pessoas fazem de suas vidas. A ciência social tem uma longa tradição de análise teórica e de pesquisa na área. $O$ construto tem tido um crescente interesse por parte dos pesquisadores nos últimos anos e cobre estudos que têm utilizado as mais diversas nomeações, tais como felicidade, satisfação, estado de espírito, afeto positivo, sendo também considerado por alguns autores uma avaliação subjetiva da qualidade de vida. As definições desses conceitos, e conseqüentemente sua operacionalização em termos de medida, ainda são um pouco confusas e deturpadas. Não existe um consenso entre os estudiosos do assunto, o que dificulta a investigação do BES (Diener, Suh, Lucas \& Smith, 1999; DeNeve \& Cooper, 1998).

Bem-Estar Subjetivo é um construto que também sofre influência cultural, embora a hereditariedade possa responder por cerca de 52\% da variância no BES (Lykken \& Tellegen, 1996). Concebendo cultura como experiências compartilhadas que formam a base de uma maneira similar de se ver o mundo (Heller, citado por Smith \& Bond, 1999), não há como descartar o seu papel na experiência do BES das pessoas. O sentido das experiências dos indivíduos é construído socialmente através de crenças, pressuposições e expectativas sobre

1 Fonte de financiamento: CNPq.

2 Endereço: Universidade de Brasília, Instituto de Psicologia, LabPAM, Brasília, DF, Brasil 70910-900. E-mail: anesalazar@uol.com.br o mundo (Heller, citado por Smith \& Bond, 1999). Como cultura influencia personalidade e personalidade influencia cultura, ambos os níveis de análise são fundamentais para o entendimento do BES dentro de uma perspectiva cultural. Pesquisas mostram elevadas diferenças entre nações com relação ao BES em função dos níveis de renda de cada nação (Diener, Diener \& Diener, 1995). Níveis de felicidade mais elevados foram observados, em uma primeira investigação, em culturas individualistas ricas. Schyns (1998), no entanto, não conseguiu replicar estes resultados. Infelizmente, muitos estudos transculturais não são passíveis de replicação provavelmente devido ao número reduzido de nações envolvidas e à falta de medidas longitudinais.

Mesmo assim, pessoas de países mais ricos, com maior liberdade e ênfase no individualismo, tendem a demonstrar maior BES (Diener, Diener \& Diener, 1995). É possível que os individualistas sejam mais capazes de seguir seus próprios interesses e desejos e, assim, mais freqüentemente consigam se auto-realizar. No entanto, se por um lado, nas nações individualistas, são elevados os relatos de bem-estar global, bem como a satisfação com domínios tais como casamento; por outro lado, taxas de suicídio e de divórcio também são altas. Já amostras de nações pobres revelam escores médios de BES ou até mesmo abaixo do ponto neutro. Individualistas são mais propensos a se separarem e a cometerem suicídio se as coisas não vão bem, talvez devido a menor intensidade de suporte social em culturas individualistas durante períodos 
problemáticos. Assim, individualistas podem experimentar níveis mais extremos de BES, enquanto coletivistas podem ter uma estrutura mais segura, que produz menos pessoas muito felizes, mas talvez também menos pessoas isoladas e deprimidas. De fato, ilusões positivas como auto-engrandecimento, otimismo ingênuo e percepções exageradas de controle são comuns entre norte-americanos e funcionam como mecanismos de coping para restaurar e manter saúde física e psicológica positiva dos americanos (Taylor \& Armor, 1996). Contudo, recentes estudos transculturais (Lee \& Seligman, 1997) descobriram que tais ilusões positivas não são comuns entre asiáticos, sugerindo que auto-engrandecimento e otimismo podem não conduzir a elevado BES em determinadas culturas.

As primeiras pesquisas sobre o BES foram predominantemente americanas. Com o passar dos anos, percebeu-se o papel da cultura no bem-estar e a necessidade de um entendimento das razões da variabilidade do fenômeno através de diferentes culturas, ocorrendo grande interesse por estudos transculturais. Surge, então, a demanda por novos instrumentos de medida, construídos a partir de características da cultura avaliada e, portanto, adaptados à população investigada. É possível que a carência de pesquisa empírica nessa área, no Brasil, se deva também à falta de instrumentos de medida adequados a essa cultura.

\section{Bem-estar subjetivo e outros conceitos}

BES é o estudo científico da felicidade: o que a causa, o que a destrói e quem a tem. A palavra "felicidade" expressa os componentes afetivos do BES. Alguns conceitos são empregados, no senso comum, como sinônimos de felicidade e bem-estar. Qualidade de vida, por exemplo, é muitas vezes compreendida desta forma. Na literatura médica, entretanto, o termo qualidade de vida parece não ter um único significado (Gill \& Feinstein, 1994). Expressões como "condições de saúde", "funcionamento social" e "qualidade de vida" têm sido usadas como sinônimos e a própria definição de qualidade de vida não consta na maioria dos artigos que utilizam ou propõem instrumentos para sua avaliação (Gill \& Feinstein, 1994). Qualidade de vida pode relacionar-se com saúde e estado subjetivo de saúde, considerados como conceitos afins, centrados na avaliação subjetiva do paciente, mas necessariamente ligados ao impacto do estado de saúde sobre a capacidade do indivíduo viver plenamente. De acordo com a conceituação de Gill e Feinstein (1994), qualidade de vida não inclui somente fatores relacionados à saúde, tais como bem-estar físico, funcional, emocional e mental, mas também elementos não relacionados à saúde como trabalho, família, amigos e circunstâncias de vida. Para os pesquisadores do BES, o elemento subjetivo é essencial na avaliação da qualidade de vida de um indivíduo ou de um grupo, pois os indicadores sociais por si só não seriam capazes de defini-la já que as pessoas reagem diferentemente a circunstâncias semelhantes (Diener \& Suh, 1997). BES também se distingue de saúde mental. Uma pessoa pode ser ou estar insana e se sentir muito feliz. Já outra pessoa pode estar bem em muitos aspectos de sua vida, mas não ser particularmente feliz (Diener, 2001). BES não significa necessariamente saúde psicológica, ele é apenas um aspecto do bem-estar psicológico, sendo necessário, mas não suficiente para a pessoa estar bem na vida.

BES apresenta necessariamente três características fundamentais que podem distingui-lo dos outros conceitos: a subjetividade, medidas positivas e uma avaliação global (Diener, 1984). Campbell (1976) argumenta que BES é uma experiência interna de cada indivíduo. Conseqüentemente, condições externas objetivas, tais como saúde, conforto, virtude ou riqueza, não devem fazer parte das definições do BES. Embora tais condições sejam vistas como influências potenciais no BES, elas não são consideradas como parte inerente e necessária a ele. Quanto à segunda característica, expressar aspectos positivos, não implica exatamente na ausência de fatores negativos, mas sim na predominância dos afetos positivos sobre os afetos negativos. E, por último, o terceiro aspecto significa que o BES inclui necessariamente uma avaliação global dos diversos aspectos da vida de uma pessoa.

\section{Os componentes do BES}

Apesar das discordâncias teóricas relativas a conceituação de BES, há um consenso quanto às suas dimensões: satisfação com a vida e afetos positivos e negativos (Anguas, 1997; Martinez \& Garcia, 1994). Afeto positivo é um contentamento hedônico puro experimentado em um determinado momento como um estado de alerta, de entusiasmo e de atividade. É um sentimento transitório de prazer ativo; mais uma descrição de um estado emocional do que um julgamento cognitivo. Afeto negativo refere-se a um estado de distração e engajamento desprazível que também é transitório, mas, que inclui emoções desagradáveis como ansiedade, depressão, agitação, aborrecimento, pessimismo e outros sintomas psicológicos aflitivos e angustiantes (Diener, 1995). A dimensão satisfação com a vida é um julgamento cognitivo de algum domínio específico na vida da pessoa; um processo de juízo e avaliação geral da própria vida (Emmons, 1986); uma avaliação sobre a vida de acordo com um critério próprio (Shin \& Johnson, 1978). O julgamento da satisfação depende de uma comparação entre as circunstâncias de vida do indivíduo e um padrão por ele escolhido.

Assim, BES elevado inclui freqüentes experiências emocionais positivas, rara experiência emocional negativa (depressão ou ansiedade) e satisfação não só com vários aspectos da vida, mas com a vida como um todo. Naturalmente que o humor das pessoas, suas emoções e julgamentos auto-avaliativos, mudam com a passagem do tempo, caracterizando a satisfação com a vida como um construto não só multidimensional, mas também dinâmico. Isto, no entanto, não implica na instabilidade do fenômeno. Flutuações momentâneas não obscurecem um julgamento mais abrangente do que pode ser considerado como o nível mais estável que a pessoa julga caracterizar a sua satisfação com a vida. Evidências neste sentido têm sido encontradas nos estudos sobre o desenvolvimento de instrumentos para medir o BES.

\section{Mensuração do BES}

O método mais usual de mensuração do BES consiste no uso de auto-relato onde o indivíduo julga a satisfação que 
possui com relação a sua vida e relata a freqüência de emoções afetivas recentes de prazer e desprazer (Diener, Oishi $\&$ Lucas, 2003). Medidas de auto-relato parecem particularmente apropriadas ao campo, tendo em vista que somente o indivíduo pode experimentar seus prazeres e dores e julgar se está satisfeito com sua vida. Até mesmo medidas globais do BES que simplesmente perguntam quão satisfeitas ou felizes as pessoas estão têm se mostrado válidas, com certas limitações. Essas medidas têm demonstrado propriedades psicométricas adequadas, bons índices de consistência interna, moderada estabilidade e sensibilidade apropriada a mudanças de circunstâncias de vida (Larsen, Diener \& Emmons, 1985). As escalas de BES demonstram bons índices psicométricos de validade de construto. Estimativas de fidedignidade/estabilidade apresentam correlações que variam de 0,50 a 0,70 (Diener, Suh \& Oishi, 1997). Alguns artefatos de resposta devem ser controlados na aplicação de instrumentos de auto-relato, tais como desejabilidade social. Pesquisadores devem tentar avaliar o impacto desses artefatos, sempre que possível, a fim de que as medidas de auto-relato não sofram distorções. Medidas de bem-estar devem ser administradas sob condições constantes ou sistematicamente variadas, pois a situação de mensuração pode influenciar as respostas. Valores dados ao BES podem variar dependendo do tipo de escala utilizada, a ordem dos itens, o estado de humor no momento de responder ao instrumento e outros fatores situacionais. Embora o humor momentâneo seja relevante na investigação do fenômeno, não é desejável que influencie indevidamente relatos de como a pessoa tem se sentido nos últimos meses ou anos. Eid e Diener (no prelo), entretanto, verificaram que, em situação de testagem normal, o componente estável da satisfação com a vida obscurece a influência do humor do momento.

Alguns estudos que utilizam medidas globais do BES também utilizam uma série de medidas adicionais tais como relatos informativos (o que seus amigos e sua família dizem sobre o seu BES?), medidas de memória (você pode rapidamente recordar bons eventos, e não maus eventos, num período de tempo?), entrevista e medidas qualitativas onde são coletados relatos de humor em momentos aleatórios ao longo do dia ou pelo período de algumas semanas. Algumas investigações levam em conta medidas biológicas do BES como eletroencefalogramas, eletromiografia facial e níveis de cortisol na saliva.

É esperado que medidas baseadas em diferentes metodologias correlacionem-se às medidas de relato de bemestar, pois escalas de auto-relato não são o único método para investigar o fenômeno. Ainda há poucos autores que utilizam diferentes tipos de medidas para comparar grupos ou testar teorias na área do bem-estar. Balatsky e Diener (1993), por exemplo, utilizaram uma medida de satisfação tipo auto-relato e uma medida de memória de bons e maus eventos da vida para acessar BES de americanos e russos. Os escores dos russos foram os mais baixos, tanto com o método de auto-relato quanto através do método da memória. As pesquisas demonstram que medidas diferentes levam a conclusões similares. A vantagem de medidas múltiplas é a maior confiabilidade nos resultados.

Medidas de bem-estar mostram moderada a alta estabilidade temporal. De acordo com as pesquisas de Diener, Suh e
Oishi (1997), satisfação com a vida, por exemplo, demonstra correlação de 0,58 ao longo de um período de quatro anos e sua correlação permanece forte $(0,52)$ quando relatos informativos de satisfação com a vida são substituídos na segunda testagem. Afeto positivo e afeto negativo demonstraram estabilidade por muitos anos. As medidas de BES podem ser relatos globais de um longo período de tempo, baseados na memória, ou experiências momentâneas. Para a maioria das pessoas, o passado e o futuro são mais importantes do que o instante presente, o que significa que alguns incidentes podem ser desagradáveis quando são experimentados, mas, podem ser percebidos de maneira positiva quando terminam. Um episódio que termina bem é mais provável de ser relembrado positivamente, independente de quão desagradável ele foi anteriormente. Portanto, BES inclui uma série de momentos felizes, prazerosos, assim como julgamentos globais.

Entre as escalas mais frequientemente utilizadas para mensurar o BES encontra-se a Escala de Bem-Estar Subjetivo (Subjective Well-Being Scale - SWBS) de Lawrence e Liang (1988), composta por 15 itens relativos a quatro subdimensões: satisfação de vida (congruence), felicidade (happiness), afeto positivo (positive affect) e afeto negativo (negative affect). A SWBS inclui a Escala de Satisfação com a Vida (Satisfaction with Life Scale - SWLS) de Diener, Emmons, Larsen e Griffin (1985), composta por quatro itens. Outro instrumento bastante utilizado nas pesquisas estrangeiras é a Escala de Afeto Positivo e Afeto Negativo (Positive Affect/Negative Affect Scale - PANAS) de Watson, Clark e Tellegen (1988), composta por 20 itens mensurando as dimensões afeto positivo e afeto negativo.

O objetivo deste estudo foi a construção e a análise dos primeiros índices de validade de construto de uma escala brasileira de mensuração de BES (Escala de Bem-Estar Subjetivo - EBES) que também apresenta as características já testadas e validadas em outros instrumentos de mensuração. As características propostas para a EBES são: instrumento de auto-relato, composto de itens representativos dos fatores satisfação com a vida e afeto negativo e positivo.

\section{Metodologia}

\section{Elaboração da escala}

Parte dos itens incluídos na versão inicial da EBES foi retirada de escalas já existentes no exterior, enquanto outros foram elaborados e analisados em grupos de validação semântica. Verificou-se, em um estudo com um grupo composto por trinta adolescentes do sexo feminino, alunas do segundo ano do curso de magistério de uma escola municipal (Salazar, 1996), que boa parte dos itens da Escala de Afeto Positivo e Afeto Negativo (PANAS) de Watson e cols. (1988) e da Escala de Satisfação com a Vida (SWLS) de Diener e cols. (1985), traduzidos por psicólogos bilíngües, não apresentavam clareza impedindo a compreensão dos seus significados. Além disso, o grupo também reagiu negativamente ao formato desses instrumentos, principalmente quanto à forma da apresentação das opções de respostas. Considerando-se, então, a inadequação de simples traduções de itens com claros vieses culturais, resolveu-se incluir os que foram mais bem compreendidos e elaborar novos itens 
que pudessem capturar os significados dos fatores propostos como representativos do fenômeno a partir da perspectiva da cultura brasileira. Foram utilizados três itens da Escala de Bem-Estar Subjetivo (SWBS) de Lawrence e Liang (1988), três da Escala de Satisfação com a Vida (SWLS) de Diener e cols. (1985) e quinze da Escala de Afeto Positivo e Afeto Negativo (PANAS) de Watson e cols. (1988). Portanto, foram retirados ao todo 21 itens de escalas já existentes. Para os novos itens, recorreu-se a grupos focais onde 30 estudantes universitários de diferentes cursos da Universidade de Brasília responderam as seguintes perguntas: "Como você se sente quando percebe que está feliz e satisfeito com sua vida? Como você se sente quando percebe que está infeliz e insatisfeito com sua vida?" Algumas respostas com sentido similar foram descartadas, permanecendo as mais freqüentes no grupo, o que resultou em 48 novos itens correspondentes às três dimensões sugeridas (afeto positivo, afeto negativo e satisfação/insatisfação com a vida).

A primeira versão da escala ficou dividida em duas subescalas. A primeira subescala, composta por 54 itens, representa sentimentos e emoções (positivos e negativos) e avalia a dimensão afeto do BES. A segunda subescala, composta por 15 sentenças, procura avaliar o que o indivíduo faz da sua própria vida e mede a dimensão satisfação com a vida. A fim de evitar problemas na apresentação da escala, criou-se uma nova formatação para a subescala de afeto positivo e afeto negativo, onde o indivíduo deve escrever ao lado da palavra que representa o construto apenas o número que corresponde à sua opção de resposta (1, 2, 3, 4 ou 5), o que faz com que o instrumento fique mais limpo e claro. Utilizou-se uma escala de resposta tipo Likert de cinco pontos para acompanhar os itens de cada subescala. Após a análise semântica do instrumento piloto, a EBES compôs-se de 69 itens. Na primeira parte da escala, os itens vão do número 1 ao 54 e descrevem afetos positivos e negativos, devendo o sujeito responder como tem se sentido ultimamente numa escala em que 1 significa nem um pouco e 5 significa extremamente. $\mathrm{Na}$ segunda parte da escala, os itens vão do número 1 ao 15 e descrevem julgamentos relativos à avaliação de satisfação ou insatisfação com a vida, devendo ser respondidos numa escala onde 1 significa discordo plenamente e 5 significa concordo plenamente (ver Anexo 1).

\section{Participantes}

A amostra total foi composta por 795 policiais civis do Distrito Federal, $74 \%$ do sexo masculino, idade média de 35,6 anos (desvio-padrão = 4,83), 60,4\% casados e 56,5\% com nível de escolaridade superior incompleto. A descrição demográfica da amostra é apresentada na Tabela 1.

\section{Procedimentos}

A primeira versão da EBES foi aplicada coletivamente em salas com no máximo 30 pessoas, no próprio local de trabalho dos participantes. O tempo de aplicação foi de aproximadamente 30 minutos. As respostas foram dadas de forma anônima, havendo apenas um número de identificação para cada participante.
Tabela 1. Dados sobre sexo, estado civil, idade e escolaridade ( $\mathrm{N}=795)$

\begin{tabular}{|c|c|c|c|}
\hline Variável & Descrição & Freqüiência & Porcentagem \\
\hline \multicolumn{4}{|l|}{ Sexo } \\
\hline & Masculino & 588 & 74 \\
\hline & Feminino & 189 & 23,8 \\
\hline & Sem resposta & 18 & 2,2 \\
\hline \multicolumn{4}{|c|}{ Estado Civil } \\
\hline & Solteiro & 148 & 18,6 \\
\hline & Casado & 480 & 60,4 \\
\hline & Separado & 57 & 7,2 \\
\hline & Viúvo & 4 & 0,5 \\
\hline & Amigado & 66 & 8,3 \\
\hline & Outros & 20 & 2,5 \\
\hline & Sem resposta & 20 & 2,5 \\
\hline \multicolumn{4}{|c|}{ Idade (anos) } \\
\hline & 23 a 30 & 105 & 13,2 \\
\hline & 31 a 40 & 562 & 70,7 \\
\hline & 41 a 50 & 99 & 12,5 \\
\hline & 51 ou mais & 5 & 0,6 \\
\hline & Sem resposta & 24 & 3,0 \\
\hline & Mínima & 23 & - \\
\hline & Máxima & 66 & - \\
\hline & Média & 35,6 & - \\
\hline & Desvio-Padrão & 4,83 & - \\
\hline \multicolumn{4}{|c|}{ Escolaridade } \\
\hline & Médio Incompleto & 130 & 16,4 \\
\hline & Médio Completo & 156 & 19,6 \\
\hline & Superior Incompleto & 449 & 56,5 \\
\hline & Superior Completo & 29 & 3,6 \\
\hline & Pós-Graduação & 5 & 0,6 \\
\hline & Sem resposta & 26 & 3,3 \\
\hline
\end{tabular}

\section{Tratamento dos dados}

A análise estatística utilizada baseou-se primeiramente na análise dos componentes principais para investigar a estrutura fatorial da matriz. A análise dos componentes principais é sugerida por Tabachnick e Fidell (2001) como uma forma de identificar o possível número de fatores (componentes) presentes na matriz de intercorrelações. Os pressupostos exigidos pelas técnicas multivariadas de análises de dados também foram verificados. Dois critérios foram utilizados para identificar o número de fatores a serem extraídos: análise do screeplot, que mostrou claramente a existência de três fatores e análise da porcentagem de variância explicada obtida a partir do acréscimo de cada fator, a qual mostrou que mais que três fatores não acrescentariam praticamente nada à explicação da variância. Procedeu-se à análise fatorial através do método de extração dos eixos principais $(P A F)$ e rotação oblimin. Optou-se pela rotação oblimin por ela permitir que apareçam fatores ortogonais quando estes existem e já que não força a dependência entre os fatores, mas apenas a permite, enquanto a rotação ortogonal só permite fatores independentes (Pasquali, no prelo). Os traços latentes em Psicologia quase nunca são independentes e a rotação oblíqua respeita este aspecto da correlação entre os fatores. Efetuouse a análise dos itens através do método da Teoria de Resposta 
ao Item (TRI) utilizado para verificar a qualidade dos itens de um instrumento, relacionando variáveis observáveis (os itens da escala) e traços hipotéticos não-observáveis (BES). Traços não-observáveis são responsáveis pelas respostas dadas às variáveis observáveis, ou seja, pelas respostas ou comportamentos emitidos pelo sujeito. A resposta do sujeito ao item vai depender do seu nível no traço latente.

\section{Resultados}

\section{Validade de construto da EBES}

A validade de construto da EBES foi analisada a partir de métodos que permitem o estabelecimento de sua estrutura fatorial. A versão proposta e analisada, neste trabalho, foi elaborada para abranger os três fatores propostos na literatura como componentes do construto BES. Para investigar a estrutura fatorial de um instrumento, é necessário verificar: (1) a adequação da matriz correlacional dos itens; (2) o número possível de fatores que melhor descrevem esta matriz e (3) a identificação da melhor solução fatorial.

Através da análise dos componentes principais, verificouse que os dados do presente estudo preenchiam os pressupostos exigidos para se proceder a uma análise fatorial: a matriz de correlação mostrou covariância suficiente para permitir a busca de fatores, o KMO foi elevado $(0,97)$. O exame do scree plot e dos eigenvalues indicou a possível existência de três fatores.

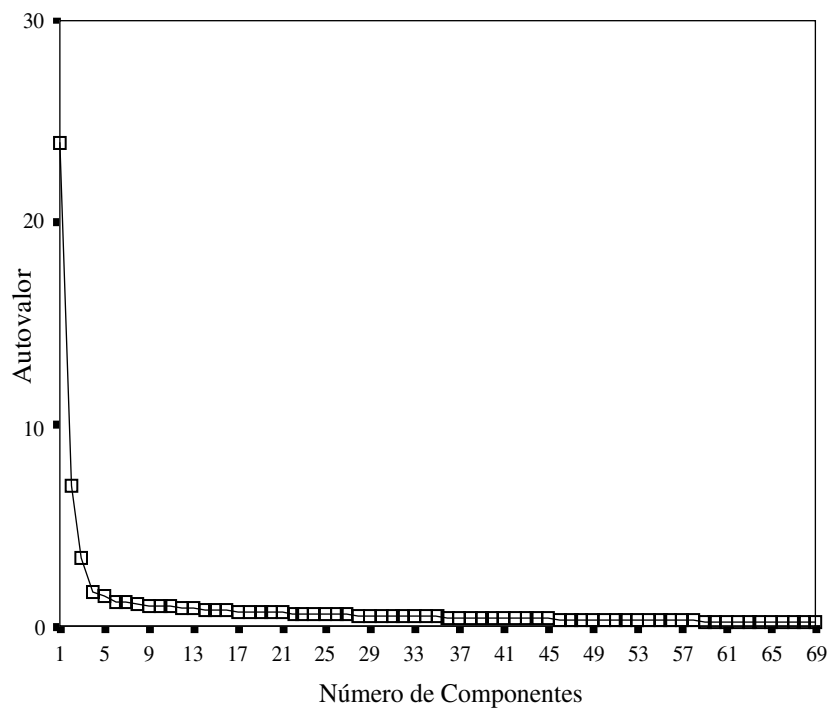

Figura 1. screeplot

Em seguida, uma análise fatorial, com o método de extração dos eixos principais e rotação oblimin, revelou que a solução dos três fatores foi a que permitiu a melhor interpretação teórica dos fatores originalmente previstos para a escala. Todos os itens da escala obtiveram cargas fatoriais acima de 0,30 em um dos três fatores identificados e no fator geral. Utilizou-se, no entanto, a carga fatorial 0,45 como critério de corte do item no respectivo fator para que os fatores sejam mais fortes e consistentes, a qual explica cerca de $20 \%$ de variância em comum entre o item e o fator. Sete itens foram excluídos $(21,22,30,35,37,42$ e 52) e os restantes foram submetidos à análise de consistência interna, com o cálculo do alfa de Cronbach.

Como pode ser visto na Tabela 2, o fator I (afeto positivo) é composto por 21 itens, responde por $24,3 \%$ da variância e seu alfa de Cronbach é de 0,95 . O fator II (afeto negativo) é composto por 26 itens, responde por $24,9 \%$ da variância e seu alfa é de 0,95 . Por fim, o fator III (satisfação com a vida versus insatisfação com a vida) é composto por 15 itens, responde por $21,9 \%$ da variância e seu alfa é de 0,90 . Juntos, os três fatores explicam $44,1 \%$ da variância total do construto. Note-se que, sendo os fatores correlacionados, a soma total de variância explicada não corresponde à soma das variâncias explicadas por cada fator.

Observaram-se correlações razoavelmente elevadas entre os fatores I e II $(r=0,36)$; I e III $(r=0,53)$; II e III $(r=0,47)$, o que sugeriu a presença de um fator geral. A análise fatorial mostrou que o fator geral, posteriormente denominado BES, é composto pelos 62 itens do instrumento, responde por $32,9 \%$ da variância e seu índice de fidedignidade (alfa de Cronbach) é de 0,86 .

\section{Análise dos itens}

Utilizou-se a Teoria de Resposta ao Item (TRI) como complementação à análise fatorial, procedendo-se à análise psicométrica dos itens da EBES e investigando-se a possibilidade desses itens cobrirem a amplitude do fenômeno estudado. Preliminarmente, investigou-se a unidimensionalidade da escala (um dos pressupostos básicos para a adoção de uma análise baseada na TRI), pois a EBES, em segunda ordem, é unidimensional, já que possui um fator geral de mensuração do construto BES. Procedeu-se, então, à investigação dos parâmetros psicométricos dos itens pelo modelo de dois parâmetros, já que o modelo de três parâmetros se aplica a testes onde existe a probabilidade de acertos aleatórios (Pasquali, 2003).

A descrição dos itens da EBES foi efetuada seguindo o modelo de dois parâmetros - Discriminação (parâmetro a, também denominado slope, inclination, dispersion) e Dificuldade (parâmetro b, também denominado location, threshold, position). O parâmetro c - resposta dada ao acaso ou "chute" - não foi avaliado, tendo em vista a natureza do fenômeno. O programa estatístico utilizado foi o PARSCALE, versão 3.0. A Tabela 3 apresenta os resultados da TRI relativos ao instrumento total.

O parâmetro de discriminação consiste no poder que o item possui de diferenciar sujeitos com magnitudes próximas no traço latente a que se refere, e possui uma métrica que varia entre 0 (nada discriminativo) até cerca de 4 (extremamente discriminativo). Na prática, esta escala varia de 0 a 2 .

A média do parâmetro discriminação foi de 0,86 e o desvio padrão 0,48. Para a avaliação dos índices de discriminação, foram utilizadas as categorias sugeridas por Baker (2001). O Quadro 1 apresenta os índices de discriminação dos itens da EBES.

A dificuldade representa o valor de teta (traço latente) que o sujeito deve ter para aceitar o item, uma probabilidade de aceitar o item fixada em 0,50, expressa em termos de escores padrões que variam de -3 (itens extremamente fáceis) até +3 (itens extremamente difíceis), passando pelo valor 0 (itens de dificuldade mediana). Parece razoável supor que 
Tabela 2. Cargas fatoriais, comunalidades $\left(\mathrm{h}^{2}\right)$, percentual de variância e alfa resultantes da Análise dos Eixos Principais (PAF) e rotação OBLIMIN sobre os itens da Escala de Bem-Estar Subjetivo (EBES)

\begin{tabular}{|c|c|c|c|c|c|c|}
\hline Item & F1(a) & $\mathbf{F} 2$ & F3 & $\mathbf{h}^{2}$ & $\begin{array}{l}\text { Fator } \\
\text { Geral }\end{array}$ & $\mathbf{h}^{2}$ \\
\hline 26 -dinâmico & $-0,83$ & - & - & 0,68 & $-0,59$ & 0,34 \\
\hline 10 - disposto & $-0,81$ & - & - & 0,65 & $-0,58$ & 0,33 \\
\hline 28 - produtivo & $-0,76$ & - & - & 0,63 & $-0,58$ & 0,34 \\
\hline 27 - engajado & $-0,76$ & - & - & 0,63 & $-0,54$ & 0,29 \\
\hline 14 - interessado & $-0,75$ & - & - & 0,58 & $-0,57$ & 0,32 \\
\hline 18 - animado & $-0,74$ & - & - & 0,69 & $-0,70$ & 0,49 \\
\hline 49 - inspirado & $-0,74$ & - & - & 0,67 & $-0,65$ & 0,42 \\
\hline 48 - vigoroso & $-0,74$ & - & - & 0,70 & $-0,65$ & 0,43 \\
\hline 16 - atento & $-0,74$ & - & - & 0,55 & $-0,52$ & 0,27 \\
\hline 19 - determinado & $-0,73$ & - & - & 0,62 & $-0,56$ & 0,31 \\
\hline 47 - empolgado & $-0,72$ & - & - & 0,69 & $-0,62$ & 0,38 \\
\hline 23 - decidido & $-0,69$ & - & - & 0,71 & $-0,58$ & 0,33 \\
\hline 32 - entusiasmado & $-0,69$ & - & - & 0,66 & $-0,68$ & 0,46 \\
\hline 04 - ativo & $-0,67$ & - & - & 0,49 & $-0,44$ & 0,19 \\
\hline 43 - estimulado & $-0,61$ & - & - & 0,59 & $-0,64$ & 0,40 \\
\hline 06 - agradável & $-0,55$ & - & - & 0,63 & $-0,55$ & 0,30 \\
\hline 24 - seguro & $-0,54$ & - & - & 0,66 & $-0,66$ & 0,44 \\
\hline 11 - contente & $-0,52$ & - & - & 0,71 & $-0,72$ & 0,51 \\
\hline 07 - alegre & $-0,48$ & - & - & 0,71 & $-0,65$ & 0,42 \\
\hline 03 - amável & $-0,48$ & - & - & 0,50 & $-0,48$ & 0,23 \\
\hline 45 - bem & $-0,48$ & - & - & 0,68 & $-0,77$ & 0,59 \\
\hline 50 - tenso & - & 0,78 & - & 0,70 & 0,67 & 0,45 \\
\hline 46 - nervoso & - & 0,76 & - & 0,66 & 0,60 & 0,36 \\
\hline 09 - preocupado & - & 0,74 & - & 0,62 & 0,50 & 0,25 \\
\hline 29 - impaciente & - & 0,74 & - & 0,63 & 0,62 & 0,38 \\
\hline 12 - irritado & - & 0,74 & - & 0,64 & 0,62 & 0,38 \\
\hline 20 - chateado & - & 0,73 & - & 0,64 & 0,64 & 0,42 \\
\hline 05 - angustiado & - & 0,68 & - & 0,63 & 0,68 & 0,46 \\
\hline 40 - aborrecido & - & 0,67 & - & 0,65 & 0,67 & 0,45 \\
\hline 08 - apreensivo & - & 0,67 & - & 0,58 & 0,48 & 0,23 \\
\hline 25 - assustado & - & 0,67 & - & 0,51 & 0,44 & 0,20 \\
\hline 13 - deprimido & - & 0,65 & - & 0,65 & 0,70 & 0,49 \\
\hline 01 - aflito & - & 0,65 & - & 0,52 & 0,57 & 0,33 \\
\hline 41 - agressivo & - & 0,64 & - & 0,57 & 0,54 & 0,30 \\
\hline 34 - ansioso & - & 0,64 & - & 0,45 & 0,44 & 0,20 \\
\hline 17 - transtornado & - & 0,64 & - & 0,49 & 0,51 & 0,26 \\
\hline 39 - amedrontado & - & 0,63 & - & 0,51 & 0,49 & 0,24 \\
\hline 38 - abatido & - & 0,61 & - & 0,58 & 0,65 & 0,43 \\
\hline 31 - receoso & - & 0,61 & - & 0,44 & 0,47 & 0,23 \\
\hline 44 - incomodado & - & 0,61 & - & 0,53 & 0,62 & 0,38 \\
\hline 53 - agitado & - & 0,61 & - & 0,41 & 0,33 & 0,11 \\
\hline 51 - triste & - & 0,58 & - & 0,67 & 0,73 & 0,53 \\
\hline 02 - alarmado & - & 0,57 & - & 0,41 & 0,40 & 0,16 \\
\hline 33 - desanimado & - & 0,56 & - & 0,63 & 0,73 & 0,53 \\
\hline 36 - indeciso & - & 0,52 & - & 0,46 & 0,56 & 0,32 \\
\hline 15 - entediado & - & 0,52 & - & 0,46 & 0,58 & 0,34 \\
\hline 54 - envergonhado & - & 0,47 & - & 0,31 & 0,34 & 0,12 \\
\hline 69 - Considero-me uma pessoa feliz & - & - & $-0,75$ & 0,65 & $-0,65$ & 0,42 \\
\hline 55 - Estou satisfeito com minha vida & - & - & $-0,73$ & 0,57 & $-0,58$ & 0,34 \\
\hline 61 - A minha vida está de acordo com o que desejo para mim & - & - & $-0,73$ & 0,60 & $-0,55$ & 0,30 \\
\hline 63 - Minha vida está ruim & - & - & 0,67 & 0,62 & 0,65 & 0,42 \\
\hline 60 - Tenho conseguido tudo o que esperava da vida & - & - & $-0,64$ & 0,49 & $-0,41$ & 0,17 \\
\hline 62 - Gosto da minha vida & - & - & $-0,63$ & 0,53 & $-0,58$ & 0,34 \\
\hline 67 - Minha vida é "sem graça" & - & - & 0,59 & 0,64 & 0,65 & 0,43 \\
\hline 66 - Tenho mais momentos de tristeza do que de alegria na minha vida & - & - & 0,56 & 0,59 & 0,61 & 0,37 \\
\hline 56 - Tenho aproveitado as oportunidades da vida & - & - & $-0,56$ & 0,49 & $-0,51$ & 0,26 \\
\hline
\end{tabular}


Tabela 2. Cargas fatoriais, comunalidades $\left(\mathrm{h}^{2}\right)$, percentual de variância e alfa resultantes da Análise dos Eixos Principais (PAF) e rotação OBLIMIN sobre os itens da Escala de Bem-Estar Subjetivo (EBES)

\begin{tabular}{|c|c|c|c|c|c|c|}
\hline Item & F1(a) & $\mathbf{F 2}$ & $\mathbf{F 3}$ & $\mathbf{h}^{2}$ & $\begin{array}{l}\text { Fator } \\
\text { Geral }\end{array}$ & $\mathbf{h}^{2}$ \\
\hline 57 - Avalio minha vida de forma positiva & - & - & $-0,56$ & 0,48 & $-0,54$ & 0,29 \\
\hline 64 - Estou insatisfeito com minha vida & - & - & 0,54 & 0,44 & 0,50 & 0,25 \\
\hline 65 - Minha vida poderia estar melhor & - & - & 0,53 & 0,33 & 0,33 & 0,11 \\
\hline 58 - Sob quase todos os aspectos minha vida está longe do meu ideal de vida & - & - & 0,52 & 0,33 & 0,41 & 0,17 \\
\hline 68 - Minhas condições de vida são muito boas & - & - & $-0,52$ & 0,29 & $-0,37$ & 0,14 \\
\hline 59 - Mudaria meu passado se eu pudesse & - & - & 0,50 & 0,31 & 0,41 & 0,17 \\
\hline Autovalor & 15,07 & 15,46 & 13,62 & & 20,45 & \\
\hline \% de variância & 24,31 & 24,93 & 21,97 & - & 32,99 & - \\
\hline Número de itens & 21 & 26 & 15 & - & 62 & - \\
\hline Alfa de Cronbach & 0,95 & 0,95 & 0,90 & - & 0,86 & - \\
\hline
\end{tabular}

Tabela 3. Índices de discriminação e dificuldade dos itens de acordo com o método da Teoria de Resposta ao Item (TRI)

\begin{tabular}{|c|c|c|}
\hline Item & Discriminação e E.P.E. & Dificuldade e E.P.E. \\
\hline 01 & $0,45(0,02)$ & $1,98(0,10)$ \\
\hline 02 & $0,41(0,03)$ & $3,11(0,15)$ \\
\hline 03 & $1,41(0,05)$ & $-1,13(0,03)$ \\
\hline 04 & $1,50(0,06)$ & $-1,70(0,03)$ \\
\hline 05 & $0,46(0,02)$ & $1,66(0,09)$ \\
\hline 06 & $1,67(0,07)$ & $-1,16(0,03)$ \\
\hline 07 & $1,37(0,05)$ & $-1,25(0,03)$ \\
\hline 08 & $0,57(0,02)$ & $0,99(0,07)$ \\
\hline 09 & $0,63(0,02)$ & $0,58(0,06)$ \\
\hline 10 & $1,74(0,07)$ & $-1,54(0,03)$ \\
\hline 11 & $1,39(0,05)$ & $-1,32(0,03)$ \\
\hline 12 & $0,46(0,02)$ & $2,04(0,10)$ \\
\hline 13 & $0,37(0,02)$ & $3,04(0,15)$ \\
\hline 14 & $1,57(0,06)$ & $-1,41(0,03)$ \\
\hline 15 & $0,41(0,02)$ & $2,10(0,11)$ \\
\hline 16 & $1,51(0,06)$ & $-1,53(0,03)$ \\
\hline 17 & $0,32(0,03)$ & $4,65(0,30)$ \\
\hline 18 & $1,61(0,06)$ & $-1,26(0,03)$ \\
\hline 19 & $1,40(0,05)$ & $-1,67(0,03)$ \\
\hline 20 & $0,50(0,02)$ & $1,75(0,08)$ \\
\hline $21 *$ & $0,37(0,02)$ & $2,34(0,13)$ \\
\hline $22 *$ & $1,02(0,04)$ & $-1,51(0,04)$ \\
\hline 23 & $1,44(0,05)$ & $-1,59(0,03)$ \\
\hline 24 & $1,36(0,05)$ & $-1,49(0,03)$ \\
\hline 25 & $0,43(0,03)$ & $3,27(0,15)$ \\
\hline 26 & $1,64(0,06)$ & $-1,25(0,03)$ \\
\hline 27 & $1,49(0,06)$ & $-1,24(0,03)$ \\
\hline 28 & $1,67(0,07)$ & $-1,54(0,03)$ \\
\hline 29 & $0,47(0,02)$ & $1,29(0,08)$ \\
\hline $30 *$ & $1,15(0,04)$ & $-1,49(0,04)$ \\
\hline 31 & $0,56(0,02)$ & $1,29(0,07)$ \\
\hline 32 & $1,43(0,05)$ & $-1,06(0,03)$ \\
\hline 33 & $0,38(0,02)$ & $2,72(0,13)$ \\
\hline 34 & $0,53(0,02)$ & $0,83(0,07)$ \\
\hline $35 *$ & $0,86(0,03)$ & $-1,03(0,04)$ \\
\hline 36 & $0,44(0,02)$ & $2,20(0,10)$ \\
\hline
\end{tabular}

Tabela 3. Índices de discriminação e dificuldade dos itens de acordo com o método da Teoria de Resposta ao Item (TRI)

\begin{tabular}{|c|c|c|}
\hline Item & Discriminação e E.P.E. & Dificuldade e E.P.E. \\
\hline $37 *$ & $1,04(0,04)$ & $-1,09(0,04)$ \\
\hline 38 & $0,40(0,02)$ & $2,77(0,13)$ \\
\hline 39 & $0,41(0,03)$ & $3,87(0,21)$ \\
\hline 40 & $0,46(0,02)$ & $2,40(0,11)$ \\
\hline 41 & $0,43(0,03)$ & $3,13(0,15)$ \\
\hline $42 *$ & $0,07(0,10)$ & $3,61(0,29)$ \\
\hline 43 & $1,19(0,04)$ & $-0,88(0,03)$ \\
\hline 44 & $0,47(0,02)$ & $1,83(0,09)$ \\
\hline 45 & $1,38(0,05)$ & $-1,39(0,03)$ \\
\hline 46 & $0,46(0,02)$ & $2,10(0,10)$ \\
\hline 47 & $1,20(0,04)$ & $-0,91(0,03)$ \\
\hline 48 & $1,32(0,05)$ & $-1,12(0,03)$ \\
\hline 49 & $1,36(0,05)$ & $-0,95(0,03)$ \\
\hline 50 & $0,48(0,02)$ & $1,65(0,09)$ \\
\hline 51 & $0,39(0,02)$ & $2,84(0,14)$ \\
\hline $52 *$ & $1,30(0,05)$ & $-0,92(0,03)$ \\
\hline 53 & $0,49(0,02)$ & $1,00(0,08)$ \\
\hline 54 & $0,37(0,03)$ & $3,94(0,22)$ \\
\hline 55 & $0,98(0,04)$ & $-1,93(0,04)$ \\
\hline 56 & $1,01(0,04)$ & $-1,65(0,04)$ \\
\hline 57 & $1,44(0,06)$ & $-2,18(0,03)$ \\
\hline 58 & $0,53(0,02)$ & $1,03(0,07)$ \\
\hline 59 & $0,39(0,02)$ & $0,32(0,10)$ \\
\hline 60 & $0,82(0,03)$ & $-1,25(0,05)$ \\
\hline 61 & $0,87(0,03)$ & $-1,13(0,04)$ \\
\hline 62 & $1,29(0,06)$ & $-2,31(0,03)$ \\
\hline 63 & $0,42(0,02)$ & $2,49(0,12)$ \\
\hline 64 & $0,36(0,02)$ & $2,26(0,13)$ \\
\hline 65 & $0,51(0,02)$ & $-1,24(0,07)$ \\
\hline 66 & $0,44(0,02)$ & $2,06(0,10)$ \\
\hline 67 & $0,43(0,02)$ & $2,18(0,10)$ \\
\hline 68 & $1,00(0,04)$ & $-1,67(0,04)$ \\
\hline 69 & $1,20(0,05)$ & $-2,00(0,04)$ \\
\hline
\end{tabular}

Nota. $*=$ itens retirados da escala final. Discriminação: média $=0,87$; desvio-padrão $=0,48(\mathrm{~N}=69)$. Dificuldade: média $=0,38$; desvio-padrão $=1,96(\mathrm{~N}=69)$ 
Quadro 1. Classificação dos itens da EBES de acordo com seus índices de discriminação

\begin{tabular}{|c|c|c|c|}
\hline Discriminação & Pontos de corte & Itens & $\%$ de Itens \\
\hline Nenhuma & 0 & - & - \\
\hline Muito Baixa & 0,01 a 0,34 & 17 & 1,61 \\
\hline Baixa & 0,35 a 0,64 & $\begin{array}{l}01,02,05,08,09,12,13,15,20,23,27,28,30,31,32,33,34,35,36,38,40,44,45,46 \text {, } \\
47,51,52,56,57,58,59,60\end{array}$ & 51,61 \\
\hline Moderada & 0,65 a 1,34 & $37,41,42,48,49,53,54,55,61,62$ & 16,14 \\
\hline Alta & 1,35 a 1,69 & $03,04,06,07,11,14,16,18,19,21,22,24,25,26,29,39,43,50$ & 29,03 \\
\hline Muito Alta & 1,70 ou mais & 10 & 1,61 \\
\hline Perfeita & Infinito + & - & - \\
\hline
\end{tabular}

Quadro 2. Classificação dos itens da EBES de acordo com suas dimensões e índices de dificuldade

\begin{tabular}{|c|c|c|c|c|c|c|c|}
\hline Faixa & Ponto z de corte & Interpretação & \multicolumn{3}{|l|}{ Afeto Positivo } & $\%$ Obtida & \% Esperada \\
\hline I & $<-1,28$ & Extremamente fáceis & \multicolumn{3}{|c|}{$04,10,11,18,21,22,26,39$} & 38,09 & 10 \\
\hline II & $-1,28 a-0,52$ & Fáceis & \multicolumn{3}{|c|}{$03,06,07,14,15,16,24,25,29,37,41,42,43$} & 61,91 & 20 \\
\hline III & $-0,52$ a 0,52 & Medianos & \multicolumn{3}{|c|}{-} & - & 40 \\
\hline IV & 0,52 a 1,28 & Difíceis & \multicolumn{3}{|c|}{-} & - & 20 \\
\hline $\mathrm{V}$ & $>1,28$ & Extremamente difíceis & \multicolumn{3}{|c|}{-} & - & 10 \\
\hline Faixa & Ponto $\mathrm{z}$ de corte & Interpretação & \multicolumn{3}{|l|}{ Afeto Negativo } & $\%$ Obtida & \% Esperada \\
\hline I & $<-1,28$ & Extremamente fáceis & \multicolumn{3}{|c|}{-} & - & 10 \\
\hline II & $-1,28$ a $-0,52$ & Fáceis & \multicolumn{3}{|c|}{-} & - & 20 \\
\hline III & $-0,52$ a 0,52 & Medianos & \multicolumn{3}{|c|}{-} & - & 40 \\
\hline IV & 0,52 a 1,28 & Difíceis & \multicolumn{3}{|l|}{$08,09,31,46$} & 15,39 & 20 \\
\hline V & $>1,28$ & Extremamente difíceis & \multicolumn{3}{|c|}{$\begin{array}{l}01,02,05,12,13,15,17,20,23,27,28,30,32,33,34,35 \\
36,38,40,44,45,47\end{array}$} & 84,61 & 10 \\
\hline Faixa & Ponto $\mathrm{z}$ de corte & Interpretação & $\begin{array}{l}\text { Satisfação } \\
\text { com a vida }\end{array}$ & $\%$ Obtida & $\begin{array}{l}\text { Insatisfação } \\
\text { com a vida }\end{array}$ & $\%$ Obtida & \% Esperada \\
\hline I & $<-1,28$ & Extremamente fáceis & $\begin{array}{l}48,49,50,55 \\
61,62\end{array}$ & 75 & - & - & 10 \\
\hline II & $-1,28$ a $-0,52$ & Fáceis & 53,54 & 25 & 58 & 14,29 & 20 \\
\hline III & $-0,52$ a 0,52 & Medianos & - & - & 52 & 14,29 & 40 \\
\hline IV & 0,52 a 1,28 & Difíceis & - & - & 51 & 14,29 & 20 \\
\hline $\mathrm{V}$ & $>1,28$ & Extremamente difíceis & - & - & $56,57,59,60$ & 57,13 & 10 \\
\hline
\end{tabular}

um sujeito que tem maior BES, isto é, que possui um nível mais elevado do processo latente que um dado item mede, terá uma probabilidade maior de dizer sim a este item do que um sujeito com nível inferior de BES. O Quadro 2 apresenta os índices de dificuldade dos itens da EBES.

\section{Discussão}

Como previsto, a análise fatorial identificou três dimensões capazes de explicar $44,1 \%$ da variância total do fenômeno BES. Para representar os fatores, foram mantidos 62 itens dos 69 propostos no instrumento piloto. Os itens que permaneceram se mostraram bastante representativos dos fatores aos quais pertencem (cargas fatoriais elevadas). Os fatores afeto positivo, afeto negativo e satisfação versus insa- tisfação com a vida correspondem aos fatores encontrados por Andrews e Withey (1976) e Lucas, Diener e Suh (1996).

Alguns autores têm considerado medidas de afeto (que incluem fator positivo e fator negativo) como traço de personalidade e tais medidas geralmente mostram consistência interna e trans-situacional (Diener \& Larsen, 1984). Há diversos instrumentos de afeto que contém uma versão de traço geral, como por exemplo, a Escala de Watson e cols. (1988) denominada Escala de Afeto Positivo e Afeto Negativo - PANAS, da qual foram retirados alguns itens para a construção da EBES. Afeto positivo e negativo seriam dimensões independentes ou pólos opostos de uma única dimensão? Essa questão polêmica ao longo da literatura vem apontando a necessidade da realização de mais estudos para replicação de alguns achados. Watson e cols. (1988), 
por exemplo, consideram afeto positivo e afeto negativo como duas dimensões altamente distintas que podem ser significativamente representadas como dimensões ortogonais em estudos de análise fatorial do afeto, embora os termos possam sugerir que estes dois fatores sejam opostos (fortemente inversamente correlacionados). Para Bradburn (1969), afeto positivo e negativo são relativamente independentes um do outro e não opostos como se imaginava. No nível individual, significa dizer que uma pessoa pode estar sentindo tanto altos níveis de afeto prazeroso quanto baixos níveis de afeto desagradável, como também, pode haver pessoas que experimentem baixos níveis de afeto prazeroso e desprazível, ou vice-versa. Em estudos recentes da estrutura fatorial da dimensão afeto do BES, afeto positivo e afeto negativo têm aparecido consistentemente como duas dimensões dominantes e relativamente independentes (Watson \& cols., 1988; Diener, Smith \& Fujita, 1995). Os resultados das análises da EBES não contradizem os estudos apresentados, mostrando que seus componentes afeto positivo e afeto negativo são inversamente correlacionados (não fortemente), apesar de claramente separados.

Um elevado número de outros tipos de escalas, denominadas escalas de humor, foram desenvolvidas para medir os fatores afeto positivo e afeto negativo. Muitas dessas medidas, entretanto, são inadequadas, mostrando baixa fidedignidade ou baixa validade convergente ou discriminante (Watson \& cols., 1988), o que não ocorreu com a EBES. Estudos apresentados em congressos demonstraram elevada correlação entre a EBES e outras medidas como suporte social, personalidade e estilos de coping (Salazar, 2001; Tróccoli, Salazar \& Vasconcelos, 2002; Tróccoli \& Salazar, 2003). A escala de auto-relato construída também demonstrou elevados índices de consistência interna em suas dimensões, correspondendo à posição de Larsen e cols. (1985) segundo a qual os instrumentos de auto-relato demonstram propriedades psicométricas adequadas e bons índices de consistência interna.

Com relação ao fator satisfação com a vida, observa-se que muitas das escalas existentes foram desenvolvidas consistindo apenas de um único item, o que acarreta diversos problemas psicométricos (Diener, 1984). Ademais, a maioria das escalas existentes é destinada a populações geriátricas e geralmente não medem apenas satisfação com a vida, mas incluem também outros fatores. $O$ fator satisfação com a vida da EBES consiste de 15 itens com o intuito de abarcar a dimensão em toda a sua amplitude, restringindo-se apenas à mensuração de satisfação com a vida para a população em geral, independente de variáveis específicas como a idade, por exemplo.

Os itens da EBES mostraram-se, em sua quase totalidade, capazes de diferenciar sujeitos com magnitudes próximas de BES (discriminação adequada). Com relação à dificuldade do instrumento, pôde-se perceber que os itens se distribuíram inadequadamente nas faixas esperadas. Todos os itens relativos à dimensão afeto positivo mostraram-se extremamente fáceis ou fáceis, enquanto os itens de afeto negativo mostraram-se, em sua totalidade, extremamente dificeis ou dificeis. É possível que esse resultado decorra da necessidade de se estabelecer uma tabela de faixas diferente para variáveis politômicas (já que a existente é para variáveis com proba- bilidade de acertos aleatórios), ou seja, um produto cultural. Talvez seja bem mais fácil para o brasileiro dizer sim a um afeto positivo (sinto-me ultimamente bastante alegre) do que dizer sim a um afeto negativo (sinto-me ultimamente bastante triste) ou, ainda, concordar plenamente com uma sentença do tipo estou satisfeito com minha vida, ao invés de concordar plenamente com uma sentença do tipo mudaria meu passado se pudesse. Não parece uma influência de desejabilidade social, mas, talvez, uma influência cultural que só poderia ser investigada através de um estudo transcultural. Talvez seja possível supor que a distribuição dos itens com relação ao parâmetro da dificuldade possa ser um pouco diferente com a aplicação da escala em uma amostra de pacientes clínicos depressivos. Não foram encontradas pesquisas com relatos de análises dessa natureza sobre os itens dos instrumentos de mensuração do BES. Diante disso, a questão relativa à dificuldade dos itens permanece em discussão.

Em resumo, a EBES mostrou-se um instrumento válido e preciso, o que recomenda seu uso para a avaliação de BES em populações não desviantes da normalidade em termos de saúde mental. A EBES atende à recomendação de Diener e cols. (1999) com relação à construção de instrumentos de medida de BES que possam avaliar separadamente os seus componentes. Entretanto, faz-se necessário verificar se a mesma configuração fatorial se mostra invariante em amostras diversificadas em termos profissionais e também em amostras clínicas.

\section{Referências}

Albuquerque, A. S. (1996). O bem-estar subjetivo na adolescência. Monografia não-publicada, Universidade Federal do Rio de Janeiro, Rio de Janeiro.

Albuquerque, A. S. (2001). Aspectos teóricos sobre a relação entre suporte social e bem-estar subjetivo [Resumo]. Em Universidade Federal da Bahia (Org.), Anais do II Congresso Norte Nordeste (p. 25). Salvador: UFBA.

Andrews, F. M. \& Withey, S. B. (1976). Social indicators of wellbeing. New York. Plenum Press.

Anguas, A. (1997). El significado del bienestar subjetivo, su valoración en México. Tesis de Maestría en Psicología Social, Universidad Nacional Autónoma de México, Madrid.

Baker, F. B. (2001). The basics of item response theory. Washington, DC: ERIC.

Balatsky, G. \& Diener, E. (1993). Subjective well-being among Russian students. Social Indicators Research, 28, 225-243.

Bradburn, N. M. (1969). The structure of psychological well-being. Chicago: Aldine.

Campbell, A. (1976). Subjective measures of well-being. American Psychologist, 31, 117-124.

DeNeve, K. M. \& Cooper, H. (1998). The happy personality: A meta-analysis of 137 personality traits and subjective wellbeing. Psychological Bulletin, 124(2), 197-229.

Diener, E. (1984). Subjective well-being. Psychological Bulletin, $95,542-575$.

Diener, E. (1995). A value based index for measuring national quality of life. Social Indicators Research, 36, 107-127.

Diener, E. (2001). Subjective well-being. Em N. J. Smelser \& P. B. Baltes (Orgs.), International encyclopedia of the social \& behavioral sciences. Oxford: Elsevier. 
Diener, E., Diener, M. \& Diener, C. (1995). Factors predicting the subjective well-being of nations. Journal of Personality and Social Psychology, 69, 851-864.

Diener, E., Emmons, R. A., Larsen, R. J. \& Griffin, S. (1985). The satisfaction with life scale. Journal of Personality Assessment, 49, 71-75.

Diener, E. \& Larsen, R. J. (1984). Temporal stability and crosssituational consistency of affective, behavioral, and cognitive responses. Journal of Personality and Social Psychology, 47, 871-883.

Diener, E., Oishi, S. \& Lucas, R. E. (2003). Personality, culture and subjective well-being: Emotional and cognitive evaluations of life. Annual Review of Psychology, 54, 403-425.

Diener, E., Smith, H. \& Fujita, F. (1995). The personality structure of affect. Journal of Personality and Social Psychology, 69, 130-141.

Diener, E. \& Suh, E. (1997). Measuring quality of life: Economic, social, and subjective indicators. Social Indicators Research, 40, 189-216.

Diener, E., Suh, E., Lucas, R. \& Smith, H. (1999). Subjective well-being: Three decades of progress. Psychological Bulletin, 125(2), 276-302.

Diener, E.; Suh, E. \& Oishi, S. (1997). Recent findings on subjective well-being. Indian Journal of Clinical Psychology, 24(1), 2541.

Eid, M. \& Diener, E. (no prelo). Mood variability measurement. Journal of Personality and Social Psychology.

Emmons, R. A. (1986). Personal strivings: An approach to personality and subjective well-being. Journal of Personality and Social Psychology, 51, 1058-1068.

Gill, T. M. \& Feinstein, A. R. (1994). A critical appraisal of the quality of quality-of-life measurements. Journal of the American Medical Association, 272(8), 619-926.

Larsen, R. J., Diener, E. \& Emmons, R. A. (1985). An evaluation of subjective well-being measures. Social Indicators Research, 17, 1-17.

Lawrence, R. H. \& Liang, J. (1988). Structural integration of the Affect Balance Scale and the Life Satisfaction Index A: Race, sex, and age differences. Psychology and Aging, 3, 375-384.

Lee, Y. T. \& Seligman, M. E. P. (1997). Are Americans more optimistic than the Chinese? Personality and Social Psychology Bulletin, 23, 32-40.
Lucas, R. E., Diener, E. \& Suh, E. (1996). Discriminant validity of well-being measures. Journal of Personality and Social Psychology, 71, 616-628.

Lykken, D. \& Tellegen, A. (1996). Happiness is a stochastic phenomenon. Psychological Science, 7, 186-189.

Martinez, M. \& Garcia, M. (1994). La autopercepción de la salud y el bienestar psicológico como indicador de calidad de vida percibida en la vejez. Revista de Psicología de la Salud, 6(1), 55-74.

Pasquali, L. (2003). Psicometria teoria dos testes na Psicologia e na Educação. Petrópolis: Ed. Vozes.

Pasquali, L. (no prelo). Análise fatorial para pesquisadores. Petrópolis: Ed. Vozes.

Schyns, P. (1998). Cross national differences in happiness: Economic and cultural factors explored. Social Indicators Research, 43, 2-26.

Shin, D. C. \& Johnson, D. M. (1978). Avowed happiness as an overall assessment of the quality of life. Social Indicators Research, 5, 475-492.

Smith, P. B. \& Bond, M. H. (1999). Culture: the neglected concept. Em P. B. Smith \& M. H. Bond. Social psychology across cultures: Analysis and perspectives, (pp. 38-69). Boston: Allyn \& Bacon.

Tabachnick, B. G. \& Fidell, L. S. (2001). Using Multivariate Statistic (4a ed.). Needham Heights, MA: Allyn \& Bacon.

Taylor, S. E. \& Armor, D. A. (1996). Positive illusions and coping with adversity. Journal of Personality, 64, 873-898.

Tróccoli, B. T. \& Salazar, A. (2003). Um estudo correlacional entre bem-estar subjetivo e estilos de coping. Trabalho apresentado no III Congresso Norte Nordeste, João Pessoa, Paraíba.

Tróccoli, B. T., Salazar, A. \& Vasconcelos, T. S. (2002). Bem-estar subjetivo e o modelo dos cinco grandes fatores. Trabalho apresentado no VI Encontro Mineiro de Avaliação Psicológica, Belo Horizonte, Minas Gerais.

Watson, D., Clark, L. A. \& Tellegen, A. (1988). Development and validation of brief measures of positive and negative affect: The PANAS Scales. Journal of Personality and Social Psychology, 54(6), 1063-1070. 


\section{Anexo 1 - Escala de Bem-Estar Subjetivo (EBES)}

\section{Subescala 1}

Gostaria de saber como você tem se sentido ultimamente. Esta escala consiste de algumas palavras que descrevem diferentes sentimentos e emoções. Não há respostas certas ou erradas. O importante é que você seja o mais sincero possível. Leia cada item e depois escreva o número que expressa sua resposta no espaço ao lado da palavra, de acordo com a seguinte escala.

\begin{tabular}{|c|c|c|c|c|}
\hline 1 & 2 & 3 & 4 & 5 \\
Nem um pouco & Um pouco & Moderadamente & Bastante & Extremamente \\
\hline
\end{tabular}

Ultimamente tenho me sentido ...

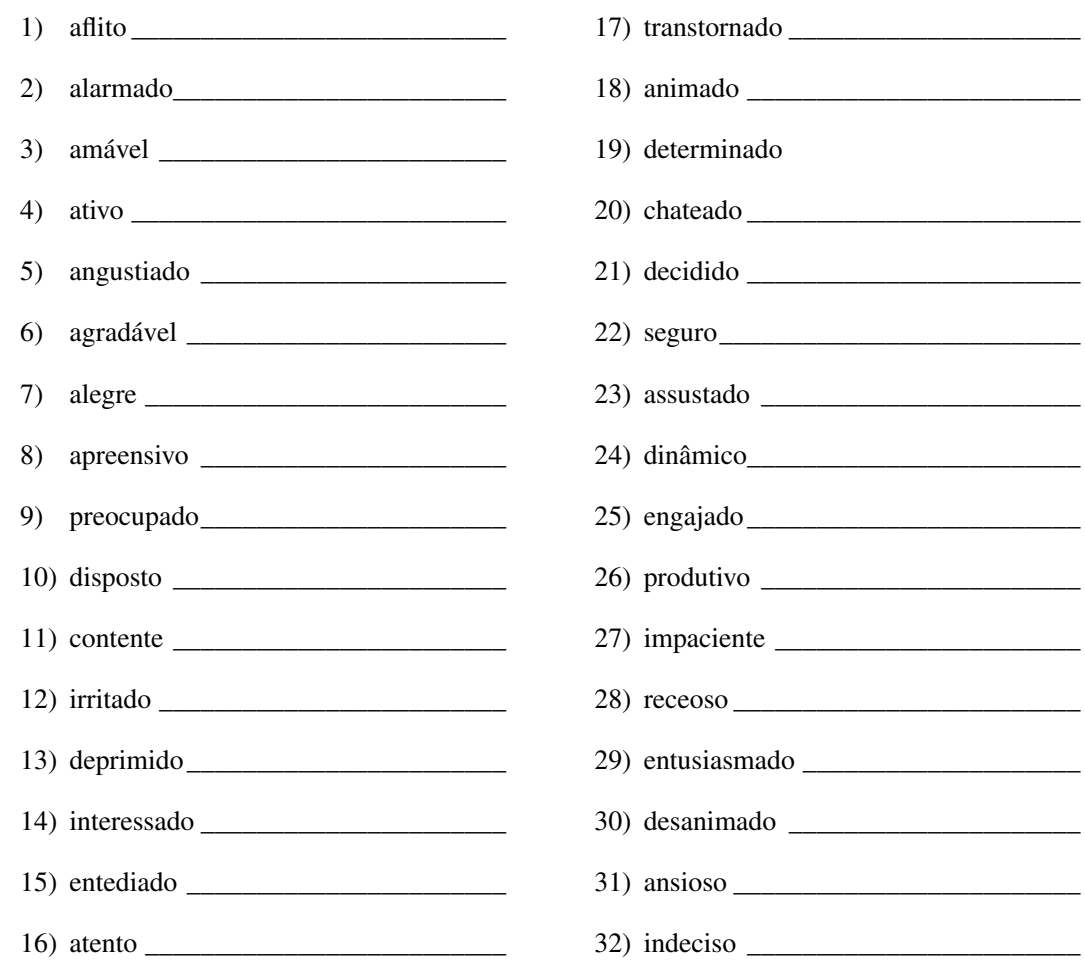

33) abatido

34) amedrontado

35) aborrecido

36) agressivo

37) estimulado

38) incomodado

39) bem

40) nervoso

41) empolgado

42) vigoroso

43) inspirado

44) tenso

45) triste

46) agitado

47) envergonhado 


\section{Subescala 2}

Agora você encontrará algumas frases que podem identificar opiniões que você tem sobre a sua própria vida. Por favor, para cada afirmação, marque com um X o número que expressa o mais fielmente possível sua opinião sobre sua vida atual. Não existe resposta certa ou errada, o que importa é a sua sinceridade.

1

\section{Discordo Plenamente}

Discordo

Não sei

Concordo

48. Estou satisfeito com minha vida

49. Tenho aproveitado as oportunidades da vida

50. Avalio minha vida de forma positiva

51. Sob quase todos os aspectos minha vida está longe do meu ideal de vida .......

52. Mudaria meu passado se eu pudesse.

53.Tenho conseguido tudo o que esperava da vida

54. A minha vida está de acordo com o que desejo para mim.

55. Gosto da minha vida

56. Minha vida está ruim

57. Estou insatisfeito com minha vida

58. Minha vida poderia estar melhor

59. Tenho mais momentos de tristeza do que de alegria na minha vida

60. Minha vida é "sem graça" .......

61. Minhas condições de vida são muito boas.

62. Considero-me uma pessoa feliz
4

5

Concordo Plenamente

|_1_|_2_|_3_|_4_|_5_|

|_1_|_2_|_3_|_4_|_5_|

|_1_|_2_|_3_|_4_|_5_|

|_1_|_2_|_3_|_4_|_5_|

|_1_|_2_|_3_|_4_|_5_|

|_1_|_2_|_3_|_4_|_5_|

|_1_|_2_|_3_|_4_|_5_|

|_1_|_2_|_3_|_4_|_5_|

|_1_|_2_|_3_|_4_|_5_|

|_1_|_2_|_3_|_4_|_5_|

|_1_|_2_|_3_|_4_|_5_|

|_1_|_2_|_3_|_4_|_5_|

|_1_|_2_|_3_|_4_|_5_|

|_1_|_2_|_3_|_4_|_5_|

|_1_|_2_|_3_|_4_|_5_| 